\title{
Sensitivity Analysis and Calibration of a Rainfall-Runoff Model with the Combined Use of EPA-SWMM and Genetic Algorithm
}

\author{
Giuseppe DEL GIUDICE and Roberta PADULANO \\ Università di Napoli Federico II, Department of Civil, Architectural \\ and Environmental Engineering, Naples, Italy; \\ e-mails: delgiudi@unina.it,roberta.padulano@unina.it
}

\begin{abstract}
An integrated Visual Basic Application interface is described that allows for sensitivity analysis, calibration and routing of hydraulichydrological models. The routine consists in the combination of three freeware tools performing hydrological modelling, hydraulic modelling and calibration. With such an approach, calibration is made possible even if information about sewers geometrical features is incomplete. Model parameters involve storage coefficient, time of concentration, runoff coefficient, initial abstraction and Manning coefficient; literature formulas are considered and manipulated to obtain novel expressions and variation ranges. A sensitivity analysis with a local method is performed to obtain information about collinearity among parameters and a ranking of influence. The least important parameters are given a fixed value, and for the remaining ones calibration is performed by means of a genetic algorithm implemented in GANetXL. Single-event calibration is performed with a selection of six rainfall events, which are chosen so to avoid non-uniform rainfall distribution; results are then successfully validated with a sequence of four events.
\end{abstract}

Key words: calibration, genetic algorithm, identification analysis, rainfall-runoff model, sensitivity analysis.

Ownership: Institute of Geophysics, Polish Academy of Sciences;

(c) 2016 del Giudice and Padulano. This is an open access article distributed under the Creative Commons Attribution-NonCommercial-NoDerivs license, http://creativecommons.org/licenses/bync-nd/3.0/. 


\section{INTRODUCTION}

Since urban areas and human activities have an impact on the natural water cycle, drainage systems have to deal with both wastewater and stormwater. Typically, the most convenient way to tackle the problem is via separated sewer systems, but in Europe (Butler and Davies 2004, Kleidorfer 2010) combined sewer systems are mainly used, where wastewater and runoff are collected in the same drainage network. To correctly dimension and manage this type of systems, engineers need reliable techniques to estimate the amount of collected water. This operation is usually difficult because of the complexity of phenomena regulating the hydrological processes and the transformation of rainfall into runoff. In an urban context, a significant complication in the development of management strategies is given by a constant increase in impervious areas (Barco et al. 2008), which implies a consequent increase in runoff volumes.

Nowadays, various models are available to manage urban runoff, including HEC-1 (US Army Corps of Engineers 1985), TR-20 and TR-55 (McCuen 1982), MOUSE (Danish Hydraulic Institute 2002), Hydroworks (H.R. Wallingford Ltd. 1997) and StormWater Management Model (SWMM) (Gironàs et al. 2010). However, these models usually require detailed information about structure and geometrical properties of a drainage network; such information is often unavailable or incomplete for widespread networks that have undergone significant changes in centuries. To enhance the quality of data, remote sensing techniques are often implemented in rainfall-runoff models to obtain realistic prediction of hydrological parameters such as rainfall spatial distribution, infiltration features, streamflow lines and land cover (Schreider et al. 2001, Aubert et al. 2003, Brocca et al. 2010, Stisen and Sandholt 2010).

In this paper, a method is presented that overcomes such a problem by adopting two different modelling levels, the first involving hydrological processes of the subcatchments, the second involving hydraulic features of the main channel. With such an approach, geometrical information is needed for the main sewer, whereas only basic information is needed for the subcatchments. Accordingly, the proposed method was built by combining together different consolidated, freeware software modules.

In the present paper, the method was tested on the Arena S. Antonio (ASA) urban basin, which is one of the largest drainage basins of Naples, Italy. The terminal section of ASA basin consists in a treatment plant that has suffered surcharge problems in the last years, because of a combination of both an uncontrolled urbanization of the area and an increasing number of high intensity rainfall events due to climate change. The plant represents the closing section of minor drainage basins as well, so that each malfunctioning 
of the plant reflects in a malfunctioning of the whole system. Thus, it is of the utmost importance to build a modelling instrument that is able to perform a realistic prevision of ASA collected runoff, in order to prevent surcharge in the treatment plant and to possibly schedule retrofitting operations within the sewer system.

\section{MODEL DESCRIPTION}

ASA is one of the most complex drainage basins within Naples drainage system, since it is made up of both urbanized and rural subcatchments, the former ones having a sewer system which is not known in detail, the latter ones being characterized by a natural, surface drainage network. The lack of detailed information about geometrical features of the sewer system is so severe that the application of consolidated hydraulic models is not straightforward. Instead, a hydrological modelling is needed for the subcatchments; however, the main sewer is suitable for a hydraulic modelling.

Provided the impossibility of applying the aforementioned hydraulic modelling tools, a Visual Basic Application interface was built that combines different tools. Specifically, three modules can be recognized:

- Hydrological module. For each subcatchment a rainfall-runoff transformation is performed with Clark's method, and each output hydrograph is applied on the main sewer as a local input. Model parameters are runoff coefficient, initial abstraction, storage coefficient and time of concentration.

- Hydraulic module. Once the subcatchments contributions have been applied along the main channel, storm water is routed within EPA-SWMM 5.0. SWMM is a dynamic rainfall-runoff simulation model used for single-event or continuous simulation of runoff quantity and quality for primarily urban areas, with many applications in non-urban areas as well. SWMM conceptualises a drainage system as a series of water and material flows among several environmental compartments (Rossman 2004). In the present paper, only the Transport Compartment was used. Thus, this model only takes Manning coefficient into account as a model parameter.

- Optimization algorithm. Calibration of the hydrologic-hydraulic model was performed using a Genetic Algorithm which solved an optimization procedure relating observed rainfall to measured runoff, basing on different rainfall events. Genetic Algorithm is a global search technique, modelled after the process of natural selection, which can be used to find near-optimal solutions to highly non-linear optimization problems (Cheng et al. 2006). In the present paper, the Genetic Algorithm implemented in GANetXL (Optimization Add-in for Microsoft Excel) (Savić et al. 2011) 
was adopted. GANetXL has already been used for many different situations in water supply networks, such as for the optimization of water supply reservoirs, of pump energy costs and turbidity at customer nodes (Bagirov et al. 2013); in these applications, the use of GANetXL is combined with EPANET (Savić et al. 2011). Single event calibration was preferred to continuous calibration because it gives an accurate reproduction of peak and hydrograph shape, whereas continuous calibration gives a better estimate of runoff volume (Tan et al. 2008). However, geometrical watershed features were considered as fixed, and not adjusted with calibration like other model parameters, which is a common technique when performing single-event calibration: when using SWMM, in particular, percentage impervious areas and subcatchment slopes are usually considered as calibration parameters (Mancipe-Munoz et al. 2011).

Available planimetric data about ASA sewer network and the related drainage areas were processed by using ArcGIS 9.3 in order to extract information about channel lengths, slopes and impervious areas; the Hydrology tool was used to derive the hydrological features of the only subcatchment that was classified as natural. GIS technology is a standard tool when building a model, since it can be, for instance, applied to obtain a spatial distribution of rainfall (Barco et al. 2008); it can also be directly interfaced with different predictive water resources models (Martin et al. 2005) and specifically with SWMM (Barco et al. 2008).

Rainfall is provided by three rain gauges. As concerns calibration, it was specifically decided to only select uniformly distributed rainfall events; this was done because rainfall spatial variability is recognized as one of the main sources of error when calibrating rainfall-runoff models (Niemczynowicz 1987). Runoff data is available at the closing section thanks to a level gauge.

\section{MODEL INPUT}

\subsection{Study area}

Arena S. Antonio is the largest drainage basin in Western Naples, having a total area of 1760 ha and a length of the main channel equal to $8.5 \mathrm{~km}$ (Fig. 1). Originally it was a stormwater sewer system, but after a strong urbanization of the area it now collects wastewater as well; the catchment is mainly urbanized, with a total percentage of impervious area equal to $62 \%$. The sewer starts from $159 \mathrm{~m}$ a.s.l., whereas its terminal section, located at Coroglio treatment plant, has an average altitude of $1 \mathrm{~m}$ a.s.l. Different cross-section configurations occur along the main sewer, with a terminal rectangular cross-section with a width of $9 \mathrm{~m}$ and a height of $3.7 \mathrm{~m}$.

With the assistance of ArcGIS it was possible to derive geometric and morphological features of every subcatchment and the hydraulic profile of 

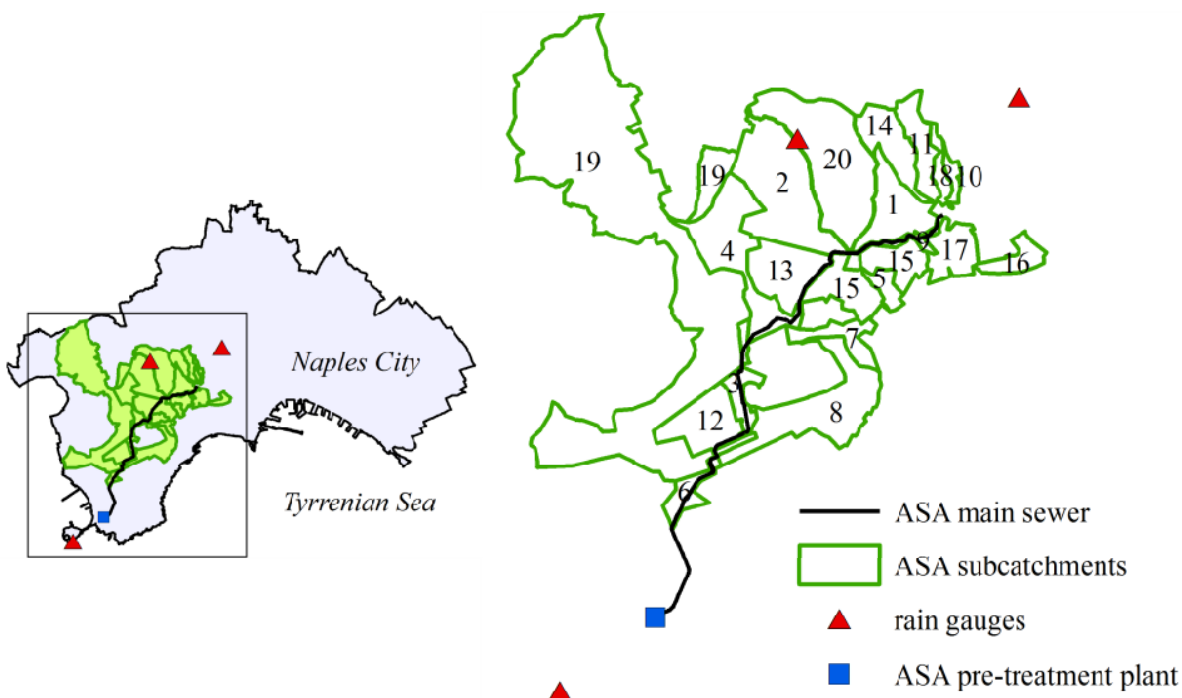

Fig. 1. Study area: main sewer, subcatchments, and rain gauges.

the sewer with its main inlets. The whole basin could be divided into 20 subcatchments, and, for each of them, percentage of urbanized area, runoff coefficient, length and average slope of the main channels were computed. Impervious areas were estimated by means of the analysis of both Corine Land Cover Map (Bossard et al. 2000) and aerial photographs commissioned by Naples City Council.

As can be seen in Table 1, the largest subcatchments are Pianura (id 19) and Verdolino (id 20) which alone account for about $50 \%$ of the whole ASA basin. All subcatchments have quite a high imperviousness rate, except for Verdolino, whose percentage of imperviousness is the smallest. Only for this subcatchment, the length of the main channel was estimated by using the Hydrology Tool available for ArcGIS 9.3. Slope information was extracted by means of a Digital Terrain Model available for the Campania Region. Average slopes range from a minimum of $0.70 \%$ for Via Cilea (id 16) to a maximum of $22.29 \%$ for Arena S. Antonio 10 (id 9).

The input file (file extension ".inp") for SWMM describing the basin main channel was built as a sequence of conduits, homogeneous in terms of geometric and hydraulic properties, and junctions. The main channel was sectioned into many portions whenever changes in slope, cross section, roughness or singularities such as drops or convergences occurred. Inputs for SWMM are the coordinates and invert elevations for each junction and cross-section shape and dimensions, length, Manning coefficient, starting and ending junction and outlet offset, if needed, for each conduit. The final 
Table 1

Characteristics of subcatchments

\begin{tabular}{|c|l|r|r|r|r|r|c|}
\hline id & Subcatchment name & $\begin{array}{c}A \\
{[\mathrm{ha}]}\end{array}$ & $\begin{array}{r}A \\
{[\%} \\
\text { ASA }]\end{array}$ & $\begin{array}{r}A_{U} \\
{[\% \text { sub- }} \\
\text { catch. }]\end{array}$ & $\begin{array}{c}I \\
{[\%]}\end{array}$ & $\begin{array}{c}K \\
{[\mathrm{~min}]}\end{array}$ & $\begin{array}{c}\varphi \\
{[-]}\end{array}$ \\
\hline 1 & Via Pigna & 62.5 & 3.6 & 52 & 5.30 & 10.1 & 0.564 \\
2 & Via Epomeo & 143.1 & 8.1 & 60 & 1.05 & 22.8 & 0.620 \\
3 & Arena S. Antonio 3 & 26.6 & 1.5 & 100 & 6.84 & 5.2 & 0.900 \\
4 & Via Pignatiello & 105.1 & 6.0 & 66 & 3.05 & 13.1 & 0.662 \\
5 & Fosso S. Stefano & 18.2 & 1.0 & 81 & 7.39 & 4.9 & 0.767 \\
6 & Arena S. Antonio 7 & 22.0 & 1.3 & 84 & 6.20 & 5.5 & 0.789 \\
7 & Via Caravaggio & 29.2 & 1.7 & 100 & 7.63 & 5.1 & 0.900 \\
8 & Via Diocleziano & 114.4 & 6.5 & 100 & 1.29 & 15.5 & 0.900 \\
9 & Arena S. Antonio 10 & 8.3 & 0.5 & 34 & 22.29 & 3.7 & 0.439 \\
10 & Via S. Giacomo dei Capri & 9.0 & 0.5 & 100 & 8.82 & 3.3 & 0.900 \\
11 & Via Jannelli & 36.7 & 2.1 & 68 & 5.44 & 7.5 & 0.676 \\
12 & Arena S. Antonio13 & 62.8 & 3.6 & 69 & 4.64 & 9.4 & 0.680 \\
13 & Arena S. Antonio15 & 85.1 & 4.8 & 87 & 6.98 & 7.9 & 0.808 \\
14 & Via Camaldolilli & 49.7 & 2.8 & 46 & 5.63 & 9.5 & 0.676 \\
15 & Viale Traiano & 81.2 & 4.6 & 68 & 6.96 & 4.9 & 0.900 \\
16 & Via Cilea & 22.7 & 1.3 & 100 & 0.70 & 14.3 & 0.900 \\
17 & Scaricatore di Via Cilea & 39.9 & 2.3 & 100 & 7.76 & 4.1 & 0.900 \\
18 & Via Mario & 14.3 & 0.8 & 100 & 3.12 & 24.2 & 0.606 \\
19 & Pianura & 668.6 & 38.0 & 58 & 11.41 & 7.4 & 0.522 \\
20 & Verdolino & 159.7 & 9.1 & 4 & 12.46 & 27.0 & 0.229 \\
\hline
\end{tabular}

model of the main channel had 149 conduits and 150 junctions (free outfall included).

As concerns subcatchments, the lack of detailed information made it impossible to reproduce their sewer network in SWMM; as a consequence, a rainfall-runoff model was applied for each of them to obtain hydrographs. Each hydrograph was then treated as a lateral inflow for the main channel and placed along it at the closing section of each subcatchment. The chosen rainfall-runoff model was the Clark's model (Clark 1945), which interprets the hydrologic response as a combination of two separate functions, translation and attenuation, reproduced by a linear channel and a single reservoir respectively. A convolution was performed between available excess rainfall data and the Clark Instantaneous Unit Hydrograph (CIUH) shown in Eq. 1, derived from the general expression under the simplifying assumption of a 
linear time-area relation, for each subcatchment $i$ (with $i$ ranging between 1 and 20):

$$
\begin{cases}u_{i}(t)=\frac{1}{t_{c i}} \cdot\left[1-e^{-t / K_{i}}\right] & \text { if } t \leq t_{c i} \\ u_{i}(t)=\frac{1}{t_{c i}} \cdot\left[e^{-t / K_{i}} \cdot\left(e^{-t / K_{i}}-1\right)\right] & \text { if } t>t_{c i}\end{cases}
$$

The parameters for Clark's model are, for each subcatchment $i$, the storage coefficient $K_{i}$ and the concentration time $t_{c i}$, both in [h]; more specifically, Clark's $t_{c}$ is the travel time required by the drop of rainfall excess at the hydraulically most remote point of the catchment to reach the channel network, as opposed to the canonical meaning of travel time to the basin outlet (Straub et al. 2000).

In spite of the availability of other hydrological models, the CIUH was adopted since it is a very effective tool for simulating the rainfall-runoff transformation, especially in catchments having unusual shapes with large length to width ratios and complex geomorphology (Sabol 1988). It is a standard simulating tool implemented in the HEC-1 (U.S. Army Corps of Engineers 1985) computer program for performing routine hydrologic studies; as part of the update from HEC-1 to HEC-HMS, a modified Clark method was created which accounts for spatial variations in rainfall and runoff on the watershed. In the present paper, however, the traditional lumped version of the model was adopted.

Many methods exist that enable the estimation of the model parameters $K$ and $t_{c}$ (Jawed 1973, Sabol 1988, Melching and Marquardt 1997, Straub et al. 2000) basing on the analysis of the hydrograph shape, or on regional analyses involving geomorphological characteristics of catchments; given the complexity of the rainfall-runoff transformation processes and the subsequent difficulty of reproducing them by means of a simple model, in the present paper $K$ and $t_{c}$ will be both considered as calibration parameters.

The storage coefficient $K$ in Clark's model accounts for the time delay between the hyetograph and the hydrograph generated by the same excess rainfall. If the single linear reservoir method is used, $K$ is equal to the time lag, which is the distance between the centroids of the two diagrams, measured on the time axis. Many empirical equations have been proposed that relate $K$ to different watershed characteristics; according to a notation by Desbordes (1975) one can distinguish between stationary formulas, just accounting for geomorphological features such as watershed area, channel length and mean slope, imperviousness percentage (Schaake et al. 1967, Rao et al. 1972, Sarma et al. 1973, Desbordes 1974, 1975; Rao and Delleur 1974, 
McEnroe and Zhao 1999, Inman 2000) and non-stationary formulas (Rao et al. 1972, Sarma et al. 1973, Rao and Delleur 1974, Desbordes 1975), also accounting for storm event features, such as duration and rainfall depth. A general relation representing such expressions, for each subcatchment $i$, is given by Eqs. 2 (stationary formula) and 3 (non-stationary formula):

$$
\begin{gathered}
K_{i}=\alpha \cdot A_{i}^{\beta} \cdot I_{i}^{\gamma} \cdot I M P_{i}^{\delta} \cdot L_{i}^{\phi} \\
K_{i}=\alpha \cdot A_{i}^{\beta} \cdot I_{i}^{\gamma} \cdot I M P_{i}^{\delta} \cdot L_{i}^{\phi} \cdot d_{i}^{\varepsilon} \cdot H_{i}{ }^{\eta}
\end{gathered}
$$

$K_{i}$ being the time lag of the subcatchment [min], $A_{i}$ the subcatchment extent [ha], $L_{i}$ the main channel length [m], $I_{i}$ its mean slope [\%], IMP $P_{i}$ the ratio of impervious to total area of the subcatchment, $d_{i}$ the duration of the storm event on the subcatchment [min], and $H_{i}$ the excess rainfall depth [mm]. Literature values suggest that stationary formulas accounting for both $A$ and $L$ are overparameterized, as only one variable is significant whereas the other seems marginal, and the sum of their exponents remains quite similar for each model; this could be due to the fact that watershed area and main channel length are closely related (Rao and Delleur 1974). In the following sections it will be considered that $\phi=0$. Besides, the influence of slope is minimal in non-stationary formulas.

As concerns time of concentration, the following formula was considered:

$$
t_{c i}=\frac{K_{i}}{c}
$$

which corresponds to the SCS formula if $c=0.6$ (McCuen 1982).

\subsection{Rainfall data}

Rainfall data were provided by CEMPID (CEntro funzionale per la previsione meteorologica e il Monitoraggio meteo.Pluvio-IDrometrico) (Centre for Weather Forecast and Rainfall-Runoff Monitoring); rainfall depths were collected via three weather stations which were the closest to the investigated area with a time pace of $10 \mathrm{~min}$.

To obtain excess rainfall from total rainfall, initial abstraction $I_{0}[\mathrm{~mm}]$ was subtracted from data and a runoff coefficient formula was conceived basing on the Wisner and P'ng's formula:

$$
\varphi_{i}=\frac{a \cdot A_{n i i}+b \cdot A_{u i}}{A_{i}}
$$


with $a$ and $b$ being dimensionless calibration parameters for the runoff coefficient, as well as $I_{0}$, which was evaluated with reference to Lim et al. (2006), Mannina et al. (2006), Thorndahl et al. (2006, 2008), and Freni et al. (2008). Equation 5 coincides with Wisner and P'ng formula (Wisner and P'ng 1983) when $a=0.2$ and $b=0.9$; also, in Eq. $5 A_{i}$ is the total area of the subcatchment, $A_{u i}$ is the urbanized area and $A_{n u i}$ is the non-urbanized area.

Basing on rainfall data recorded in 2012, ten rain events were selected that were registered by all three available rain gauges with similar values. Random differences occurring among rain gauges were neglected by adopting an average rainfall. Then, six of the ten events were sequenced in a unique, artificial event (Calibration Event, CE) with the rain events spaced one hour apart, which is the estimated drain time of the system. The remaining four events were similarly grouped in a Validation Event (VE).

\subsection{Runoff data}

Runoff data are expressed in terms of water depth in the channel crosssection; data were recorded by means of an ultrasound level gauge at the terminal section of the sewer, $80 \mathrm{~m}$ before the pre-treatment plant in Coroglio. The time step of the recording is $90 \mathrm{~s}$. As SWMM only deals with stormflow, for each month an average daily base flow was extracted by an STL (Seasonal Trend decomposition based on Loess) analysis of runoff data in dry periods, and removed from data (Cleveland et al. 1990).

\section{HYDRAULIC-HYDROLOGICAL MODEL}

Basing on the above-mentioned data, a VBA routine was built that can perform both a simple runoff simulation for fixed parameter values and a full calibration, accessing SWMM for runoff calculations and GanetXL for parameters tuning. An ExCel interface allows for setting computation features, such as: initial values and variation range for hydraulic and hydrological parameters, rainfall input data, measured runoff. In the same sheet, computed runoff values (in terms of both water depth and discharge) are written at the end of the routine, and, when measured runoff is available, efficiency indices are computed. Finally, GANetXL settings sheet was made visible, so that users can define chromosomes cell range and the objective function that must be minimized, as well as other settings for the genetic algorithm.

The model interface provides four possible efficiency indices in accordance with ASCE (1993): two of them are continuous modelling-oriented (the deviation of runoff volumes $D_{v}$ and the Nash-Sutcliffe coefficient NSE), whereas the remaining ones are single event-oriented (the percent error in peak PEP and the residuals sum of squares $G$ ) (Nash and Sutcliffe 1970, 
Green and Stephenson 1986, Martinec and Rango 1989). However, in the present paper computations were performed by minimizing only one of the proposed indices, namely the Nash-Sutcliffe coefficient NSE, which was considered as the objective function:

$$
N S E=1-\frac{\sum_{i=1}^{n}\left(Q_{i}-Q_{i}^{\prime}\right)^{2}}{\sum_{i=1}^{n}\left(Q_{i}-Q\right)^{2}}
$$

where $Q_{i}$ is the observed discharge at time $t_{i}, Q^{\prime}{ }_{i}$ is the simulated discharge at the same time, $Q$ is the average of all $Q_{i}$ values, and $n$ is the number of data. The Nash-Sutcliffe coefficient can vary between $-\infty$ and 1 , which represents the perfect fit. NSE can result in a negative value, which is meaningless in terms of data interpretation; $N S E=0$ implies the model gives no better prediction of runoff if compared to the average of observed data.

Although minimization was performed with respect to NSE, an in-depth look at the values of the other efficiency indices should be given. Indeed, a lower value of NSE does not necessarily imply poor results (Mancipe-Munoz et al. 2014), if other goodness-of-fit measures are satisfied; for example, $P E P$ is more representative for extreme flood prevision, whereas $D_{v}$ is used in runoff volume estimation models.

\subsection{Simulation}

If a simple simulation is launched, the routine acquires parameters initial values and input rainfall data for the different rainfall stations; initial abstraction is subtracted from rainfall data, average excess rainfall is computed and convolutions for each subcatchment are performed. Then, the routine completes the input file for SWMM, which was previously prepared with geometrical information representing ASA main channel, with information about subcatchments hydrographs. SWMM uses this input file to perform flow routing by means of the dynamic library swmm5.dll and prints the resulting water depths within the ExCel interface, so that a graphical representation of the output hydrograph is automatically generated. If measured water depths are available for the considered rainfall event, graphical comparison between measured and computed values is done and the proposed efficiency indices are computed for goodness-of-fit evaluation. 


\subsection{Sensitivity analysis}

One of the main problems when calibrating a model, especially with large sets of parameters, is that each parameter affects the output with a different weight, resulting in a different uncertainty that can be associated to each of them (Beven and Binley 1992). In other words, if the influence of a parameter on results is high, the reliability of its estimate will also be high, and vice versa. For parameters whose importance in the model is little, it can be convenient to consider them as constants, so that a new calibration can be performed with a smaller number of parameters, and their estimate will be even more reliable (Confalonieri et al. 2010). Procedures aiming at identifying parameters influence on the model output are called sensitivity analyses (SA), and different techniques are available in literature, differentiated in global methods and local methods (Saltelli et al. 2008). Global methods evaluate the effect of a factor while all other parameters are varied as well, and thus they account for interactions between variables and do not depend on the choice of the initial point (Kucherenko et al. 2009). A global method which is very frequent in literature is the GLUE technique, largely employed for uncertainty estimation and sensitivity analysis within environmental simulation models, thanks to its simplicity and applicability to nonlinear models; however, literature also provides some critical points of view about this popular methodology (Kuczera and Parent 1998, Mantovan and Todini 2006, Freni et al. 2008, 2009; Stedinger et al. 2008). Local methods evaluate the derivative of the model response with respect to the variation of input parameters, which are changed one at the time, by means of a model linearization. Thus, they do not directly account for interactions among variables and results are related to the initial set of parameter values. However, local methods are often used to solve identification problems in rainfall-runoff models (Mancipe-Munoz et al. 2014) mostly because the required computational effort is minimum if compared to global techniques, which are often based on Monte-Carlo simulations, so that local methods can be easily integrated in modelling software to provide a preliminary identification analysis (Kleidorfer 2010). Global methods can be adopted to enhance identification results for models with a large number of parameters, or when results of local methods need in-depth analysis.

In the present paper a local sensitivity analysis technique by Brun et al. (2001) was integrated in the VBA interface as a preliminary operation to model calibration. This methodology provides for a procedure that enables ranking of the most sensitive parameters in a model, along with an identification analysis of the whole parameter set.

Let a runoff recording be considered with a series of registered runoff depths $\eta_{i}$, with $i=1 \ldots n$, with the corresponding rainfall depth also known. 
If the proposed rainfall-runoff transformation model is applied with a parameter set $\theta_{0}=\left[\theta_{10}, \theta_{20}, \ldots, \theta_{m 0}\right]$, an output $\eta_{0}=\eta\left(\theta_{0}\right)=\left[\eta_{10}, \eta_{20}, \ldots, \eta_{n 0}\right]$ is obtained. If a different set $\theta$ is applied in the model, a different output $\eta\left(\theta_{0}\right)$ will be gained; according to Brun et al. (2001), the output $\eta\left(\theta_{0}\right)$ can be described by a linearization operation

$$
\eta(\theta)=\eta\left(\theta_{0}\right)+\left.\frac{\partial \eta(\theta)}{\partial \theta}\right|_{\theta=\theta_{0}} \cdot\left(\theta-\theta_{0}\right)=\eta\left(\theta_{0}\right)+\mathbf{V} \cdot\left(\theta-\theta_{0}\right)
$$

where $\mathbf{V}$ is the $n \times m$ derivative matrix evaluated at $\boldsymbol{\theta}_{0}$. In other words, for a parameter $\theta_{j}$ with initial value $\theta_{j 0}$, the output $\eta_{i j}$ at time $i$ is the following

$$
\eta_{i j}=\eta_{i}\left(\theta_{j}\right)=\eta_{i}\left(\theta_{j 0}\right)+\left.\frac{\partial \eta_{i}\left(\theta_{j}\right)}{\partial \theta_{j}}\right|_{\theta_{j}=\theta_{j 0}} \cdot\left(\theta_{j}-\theta_{j 0}\right)=\eta_{i}\left(\theta_{j 0}\right)+v_{i j} \cdot\left(\theta_{j}-\theta_{j 0}\right)
$$

If derivatives are expressed as finite differences, the generic derivative element $v_{i j}$ of matrix $\mathbf{V}$ can be expressed as follows

$$
v_{i j}=\left.\frac{\partial \eta_{i}\left(\theta_{j}\right)}{\partial \theta_{j}}\right|_{\theta_{j}=\theta_{j 0}}=\frac{\Delta \eta_{i}\left(\theta_{j}\right)}{\Delta \theta_{j}}=\frac{\eta_{i}\left(\theta_{j}\right)-\eta_{i}\left(\theta_{j 0}\right)}{\theta_{j}-\theta_{j 0}}
$$

Once matrix $\mathbf{V}$ is compiled, in order to preserve the dimensionless nature of the sensitivity function, it is recommended considering a dimensionless sensitivity matrix $\mathbf{S}$ with a generic element $s_{i j}$ such that

$$
s_{i j}=v_{i j} \cdot \frac{\Delta \theta_{j}}{S C}
$$

where $v_{i j}$ is the generic element in $\mathbf{V}, \Delta \theta_{j}$ is the chosen variation given to parameter $j$, and $S C$ is a scale factor accounting for possible different scales of different outputs. In the present paper, the scale factor is chosen as the mean value of the output $\eta_{0}$

$$
S C=\frac{1}{n} \sum_{i=1}^{n} \eta_{i}\left(\boldsymbol{\theta}_{0}\right)
$$

Finally, the generic element of sensitivity matrix can be computed as

$$
s_{i j}=\frac{\eta_{i}\left(\theta_{j}\right)-\eta_{i}\left(\theta_{j 0}\right)}{\theta_{j}-\theta_{j 0}} \cdot \frac{\theta_{j}-\theta_{j 0}}{S C}=\frac{\eta_{i}\left(\theta_{j}\right)-\eta_{i}\left(\theta_{j 0}\right)}{S C}
$$

Once the $\mathbf{S}$ matrix is known, some indices can be computed for each parameter: 


$$
\begin{aligned}
\delta_{j}^{m s q r} & =\sqrt{\frac{1}{n} \cdot \sum_{i=1}^{n} s_{i j}^{2}} \\
\delta_{j}^{\text {mabs }} & =\frac{1}{n} \cdot \sum_{i=1}^{n}\left|s_{i j}\right| \\
\delta_{j}^{\operatorname{mean}} & =\frac{1}{n} \cdot \sum_{i=1}^{n} s_{i j} \\
\delta_{j}^{\max } & =\max \left(s_{i j}\right) \\
\delta_{j}^{\min } & =\min \left(s_{i j}\right)
\end{aligned}
$$

Ranking the $m$ parameters by decreasing $\delta_{j}^{m s q r}$ provides a parameters importance classification that allows the identification of the most sensitive parameters. Nevertheless, such a subset does not necessarily suffice for a calibration procedure, since it is possible that a linear or near-linear dependence makes them non-identifiable even if they individually have a deep influence on the model output. To assess the degree of linear dependence among the parameters, a normalized sensitivity matrix $\widetilde{\mathbf{S}}$ must be evaluated, whose generic element $\widetilde{s}_{i j}$ can be computed as the ratio of the corresponding $s_{i j}$ to the norm of the corresponding sensitivity function:

$$
\tilde{s}_{i j}=\frac{s_{i j}}{\sqrt{\sum_{i=1}^{n} s_{i j}^{2}}}
$$

Once the normalized sensitivity matrix $\widetilde{\mathbf{S}}$ has been evaluated, the collinearity index can be computed for every subset of $p$ parameters

$$
g_{p}=\frac{1}{\min _{\|\beta=1\|}\left\|\widetilde{\mathbf{S}}_{p} \hat{\beta}\right\|}=\frac{1}{\sqrt{\lambda_{p}}}
$$

where $\hat{\beta}$ is the coefficient vector of a possible linear regression and $\widetilde{\mathbf{S}}_{p}$ is the extraction of $\widetilde{\mathbf{S}}$ referring to the $p$ parameters of interest. The denominator in the second member represents the minimum norm of the matrix $\widetilde{\mathbf{S}}_{p} \hat{\beta}$ under the condition that $\|\hat{\beta}\|=1, \lambda_{p}$ is the minimum eigenvalue of the matrix $\widetilde{\mathbf{S}}_{p}^{T} \widetilde{\mathbf{S}}_{p}$ (with $\widetilde{\mathbf{S}}_{p}^{T}$ being the transposed matrix of $\widetilde{\mathbf{S}}_{p}$ ) and $p$ is the amplitude of all the possible combinations that can be found in the subset of $m$ parameters, with $1<p \leq m$. A high value of the collinearity index $g_{p}$ (usually greater than 10-15) means that the subset of those $p$ parameters is poorly 
identifiable (Reichert and Vanrolleghem 2001, Freni et al. 2009); a collinearity index equal to 1 means that the variables are mutually independent.

Sensitivity analysis was integrated in the VBA interface; the routine provides computation of matrices $\mathbf{V}$ and $\mathbf{S}$, of indices in Eq. 13, of collinearity indices for all the possible combinations of parameters subsets and a representation of pairwise scatterplots. Also, a list of parameters according to their $\delta_{j}^{m s q r}$ values is printed.

\subsection{Calibration}

If the calibration procedure is launched, after the last step described in the Simulation section the routine access the optimization algorithm GANetXL, which chooses a different set of parameter values and repeats simulation, for a fixed number of times. Then, the algorithm selects the parameter set which minimizes the chosen objective function and the routine prints the related results within the interface. Table 2 shows GANetXL settings used in this paper.

Table 2

GANetXL settings

\begin{tabular}{|l|l|}
\hline \multicolumn{1}{|c|}{ Function call } & \multicolumn{1}{c|}{ Value } \\
\hline $\begin{array}{l}\text { Problem type } \\
\text { Population }\end{array}$ & Single-objective \\
Algorithm & \multicolumn{1}{|c|}{50} \\
Selector & Generational-elitist \\
Crossover & Tournament \\
Crossover rate & Simple one point \\
Mutator & \multicolumn{1}{|c|}{0.95} \\
Mutation rate & nimple by gene \\
Use adaptive mutation & \multicolumn{1}{|c}{ no } \\
Replacer & First weaker \\
Use simulation & \multicolumn{2}{|c}{ yes } \\
Macro name & SWMM Interface.evaluation \\
\hline
\end{tabular}

\section{DISCUSSION OF RESULTS}

Sensitivity analysis was performed by adopting the set of starting values $\boldsymbol{\theta}_{0}$ chosen by looking at the considered literature formulas (Table 3), and, as parameter variation $\Delta \boldsymbol{\theta}$, the fourth part of each variation range (Brun et al. 2001). The resulting ranking (Table 4 ) shows that the least influent parame- 
Table 3

Starting values and variation ranges

for calibration parameters

\begin{tabular}{|c|c|c|c|}
\hline & Min & Max & $\begin{array}{c}\text { Starting } \\
\text { value }\end{array}$ \\
\hline$a$ & 0.10 & 0.30 & 0.20 \\
$b$ & 0.30 & 0.90 & 0.60 \\
$c$ & 0.45 & 0.75 & 0.60 \\
$\alpha$ & 0.49 & 7.16 & 3.83 \\
$\beta$ & 0.30 & 0.54 & 0.42 \\
$\gamma$ & -0.51 & -0.08 & -0.29 \\
$\delta$ & -0.45 & -0.08 & -0.26 \\
$I_{0}$ & 0.10 & 1.00 & 0.50 \\
$n$ & 0.01 & 0.03 & 0.02 \\
\hline
\end{tabular}

Table 4

Results of sensitivity analysis

\begin{tabular}{|c|c|c|r|r|l|}
\hline & $\delta_{j}^{\text {msqr }}$ & $\delta_{j}^{\text {mabs }}$ & \multicolumn{1}{c|}{$\delta_{j}^{\text {mean }}$} & \multicolumn{1}{c|}{$\delta_{j}^{\min }$} & $\delta_{j}^{\max }$ \\
\hline$\alpha$ & 0.494 & 0.189 & 0.022 & -3.963 & 0.671 \\
$\delta$ & 0.423 & 0.150 & 0.012 & -3.509 & 0.575 \\
$\beta$ & 0.369 & 0.139 & 0.011 & -3.384 & 0.494 \\
$n$ & 0.344 & 0.205 & 0.160 & -2.440 & 0.916 \\
$\gamma$ & 0.340 & 0.125 & 0.017 & -3.172 & 0.439 \\
$b$ & 0.273 & 0.094 & 0.094 & 0.000 & 2.214 \\
$I_{0}$ & 0.150 & 0.089 & -0.089 & -1.258 & 0.000 \\
$c$ & 0.076 & 0.020 & 0.000 & -0.088 & 1.015 \\
$a$ & 0.054 & 0.025 & 0.025 & 0.000 & 0.545 \\
\hline
\end{tabular}

ters are $a$ (Eq. 5) and $c$ (Eq. 4), whose $\delta_{j}^{m s q r}$ values are way lower than the other parameters.

Figure 2 shows pairwise scatterplots for the 16 pairs of variables with the highest collinearity index $g_{2}$. It is evident from Fig. 2 that some pairs are linearly related, such as $a$ and $b$ in Eq. 5 (this is consistent with $a+b=1.1$ in Wisner and P'ng formula) and $\beta$ and $\delta$ in Eq. 2. However, the existence of deep linear dependences among some of the calibration parameters does not necessarily imply that such parameters cannot be identified: to asses this, considerations stemming from pairwise scatterplots must be enhanced by an in-depth look at the global identification conditions. 

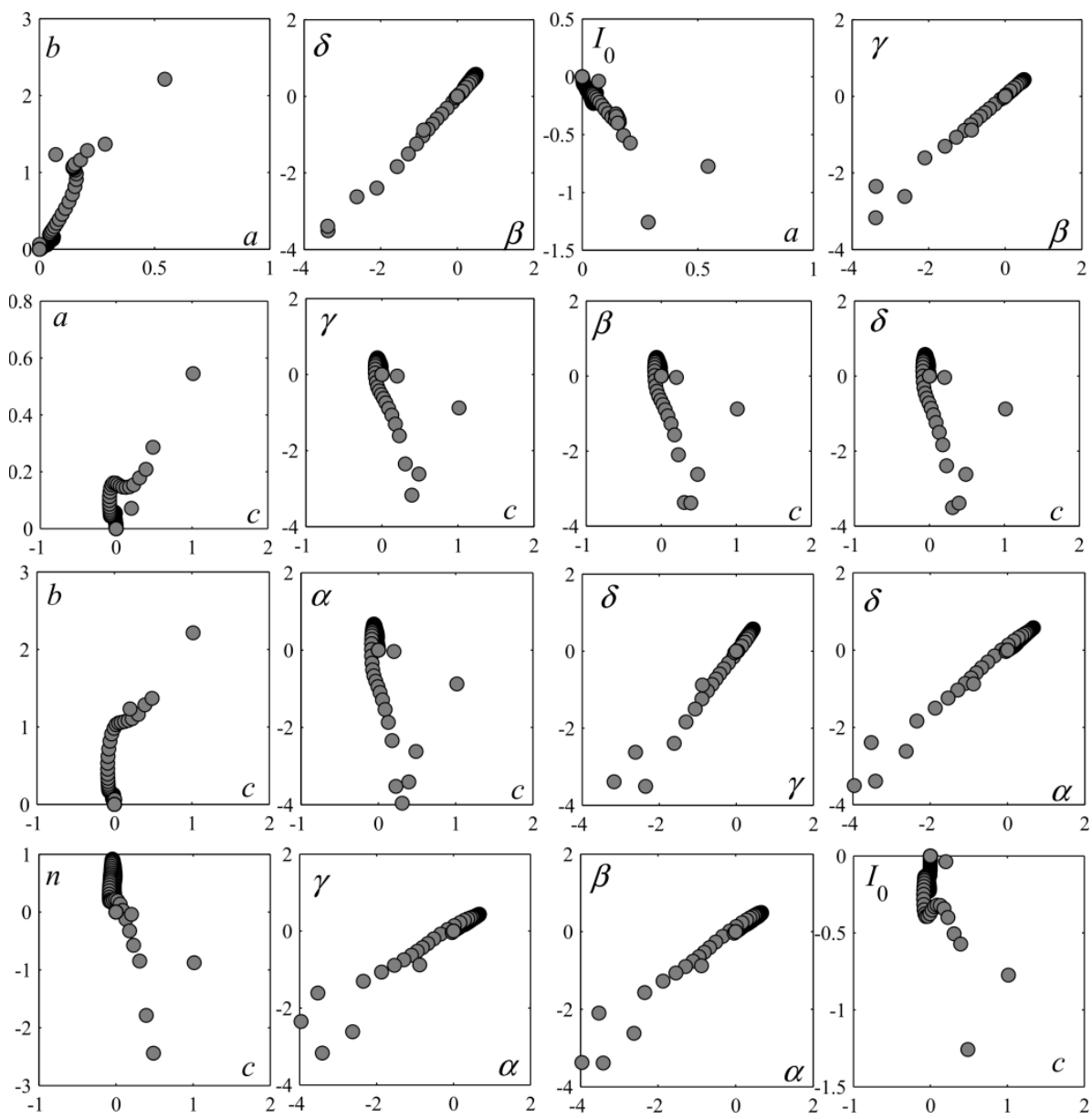

Fig. 2. Scatterplot of $s_{i j}$ for the 16 pairs of parameters with the highest collinearity index $g_{2}$ (from top-left to down-right corner).

Figure 3 shows collinearity indices $g_{p}$ for all the 502 possible combinations of the nine model parameters, with $p=2,3, \ldots, 9$. If a threshold of 10 is chosen, all the subsets are identifiable; however, because of the small number of parameters in the proposed model, a threshold of 5 is applied (Mandenius and Titchener-Hooker 2013). Consequently, all the subsets with $p \leq 4$ are clearly identifiable since their $g_{p}$ is lower or equal to the threshold value; the complete subset $(p=9)$ cannot be identified, since $g_{9}$ is higher than the threshold value. It is expected that a larger calibration set (right side of Fig. 3) provides a more accurate reproduction of data, namely of runoff recording at the basin closing section for a given rainfall event; at the oppo- 


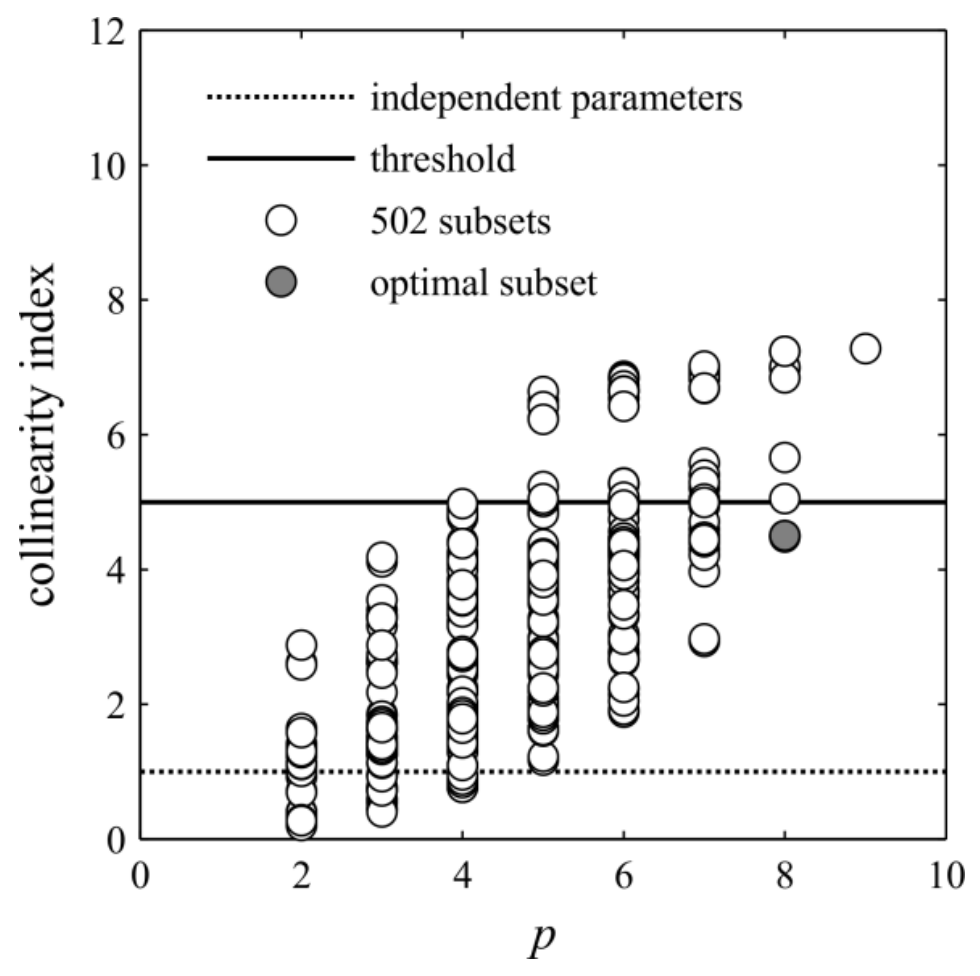

Fig. 3. Identifiability of possible parameter subsets.

site, if a small parameter set is considered (left side of Fig. 3), calibration efficiency is expected to be poor. Under these considerations, for the proposed model the subset was chosen with the largest possible dimension $p$, given that $g_{p}$ is lower than the fixed threshold. Since the subset with $p=9$ proved to be unidentifiable, for $p=8$ the only identifiable subset is the one neglecting $a$ (grey mark in Fig. 3). This is consistent with the results of both sensitivity analysis (Table 4) and pairwise scatterplots (Fig. 2), since $a$ is the parameter with the smallest influence on the model, and it is also linearly correlated with other parameters $\left(b, I_{0}\right.$ and $c$, for instance) invalidating the identification of the whole set. Accordingly, $a$ was considered as the only unidentifiable parameter in the model; in other words, the model is overparametrized only by means of $a$. Consequently, the only calibration parameters are: $\alpha, \beta, \gamma, \delta$ in the storage coefficient formula (Eq. 2), $c$ in the time of concentration formula (Eq. 4 ), $b$ in the runoff coefficient formula (Eq. 7), initial abstraction $I_{0}$ and Manning coefficient $n$.

With a constant value of $a$, equal to its literature value 0.2 , calibration was performed for each of the ten selected rainfall events, with different re- 

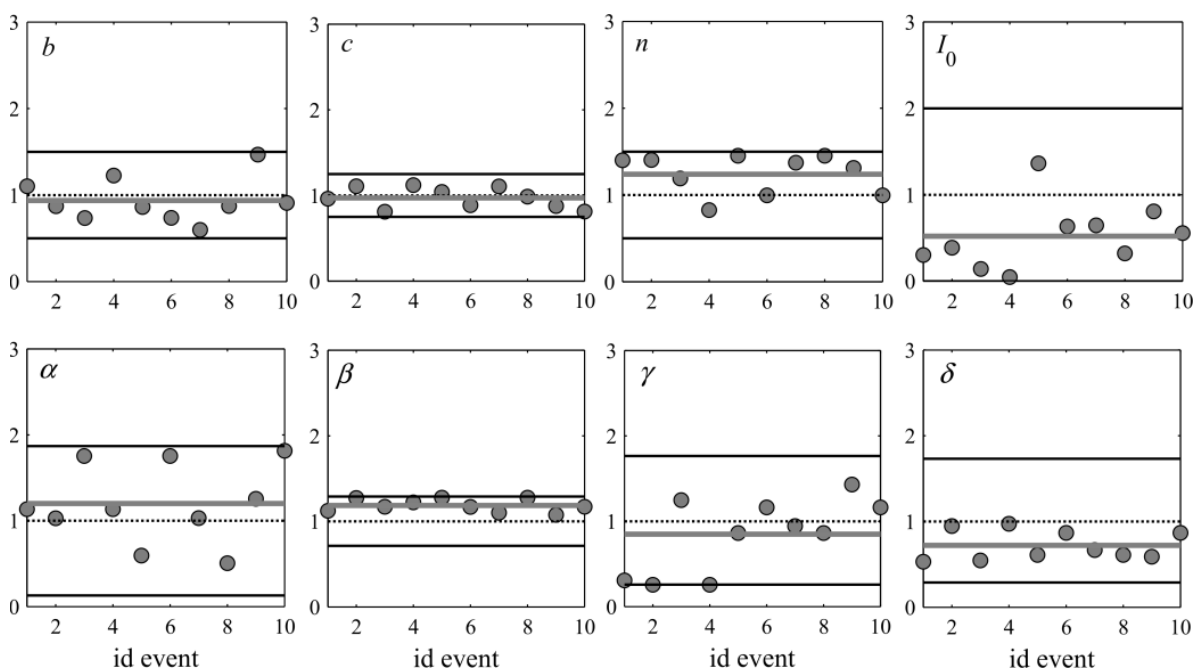

Fig. 4. Variation range (black lines), initial value (dotted line), and CE results (grey line) for calibration parameters (parameter values are adimensionalised by means of initial value).

Table 5

Parameter values after calibration of CE

\begin{tabular}{|l|c|r|}
\hline Runoff coefficient & $b$ & 0.38 \\
Time of concentration & $c$ & 0.67 \\
Storage coefficient & $\alpha$ & 5.32 \\
Storage coefficient & $\beta$ & 0.47 \\
Storage coefficient & $\gamma$ & -0.26 \\
Storage coefficient & $\delta$ & -0.25 \\
Initial abstraction & $I_{0}$ & 0.12 \\
Manning coefficient & $n$ & 0.029 \\
\hline
\end{tabular}

sults of parameter values; this was done to investigate about the variability of each parameter with respect to rainfall magnitude and characteristics. Figure 4 shows, for each model parameter, the different results adimensionalized by means of the corresponding initial value. It can be noted that, for most of the parameters, values span across the entire proposed variation range, whereas for some of them the range proves to be more extended than needed $(\beta$ and $\delta$ ). Also, $\beta$ and $c$ have the smallest variation bands. For none of the parameters the proposed range seems to be too narrow.

Once these evaluations were made, Calibration Event was used to perform a calibration to obtain definitive parameter values (Table 5). Calibrated 

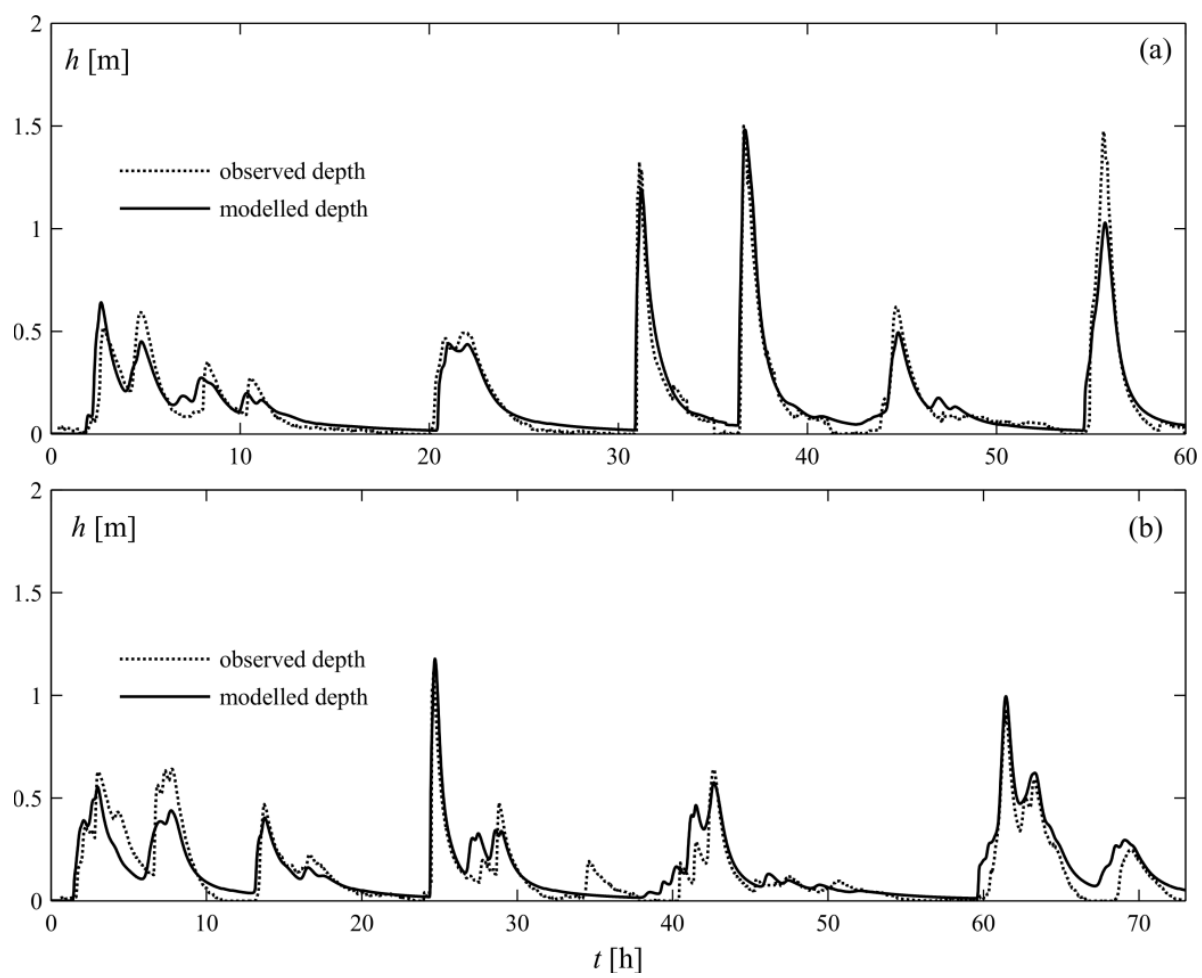

Fig. 5. Observed data and calibration results for: CE (a) and VE (b).

parameters are shown in Fig. 4 as grey lines. It can be noted that CE parameter values are roughly similar to the average of single-event values; they are also very close to the initial value line for $b, c, \alpha$, and $\gamma$ (where single-event parameters spread across the variation range) whereas a bias exists for $n, I_{0}$, $\beta$, and $\delta$ (where single-event parameters concentrate within a smaller range than the proposed one).

CE parameters were used to simulate the Validation Event, to verify the model reliability. Figure 5 shows the graphical output of the model for both $\mathrm{CE}$ and VE; it can be noted that flow reproduction is successful in both cases, as also shown by the efficiency indices values in Table 6 . It must be noted, in particular, that runoff volumes are correctly reproduced even though a single-event calibration was performed with fixed values of water sheds geometrical features. Also, the highly satisfying goodness of fit for both CE and VE implies that the model results do not depend on the specific rainfall characteristics, supporting the choice of a stationary expression for the storage coefficient, and that the assumption of rainfall spatial uniformity for the selected events is realistic. 
Table 6

Results of calibration and validation

\begin{tabular}{|c|c|c|c|c|}
\hline & $G\left[\mathrm{~m}^{2}\right]$ & PEP [\%] & $D_{v}[\%]$ & NSE [-] \\
\hline $\mathrm{CE}$ & 20.97 & -1.34 & -4.34 & 0.90 \\
$\mathrm{VE}$ & 30.14 & 0.23 & 5.70 & 0.78 \\
\hline
\end{tabular}

\section{CONCLUSIONS}

The proposed model aims at overcoming problems stemming from a general lack of details about the geometrical configuration of sewer subsystems, which hinders a straightforward application of traditional hydraulic models. On this basis, an integrated interface is described that combines different modules, each using a consolidated, freeware tool: a Visual Basic Application module that solves hydrologic convolution, EPA-SWMM for hydraulic computations along the main sewer and GANetXL as optimization algorithm. Readers interested in the interface can contact the Authors via e-mail.

Parameter tuning involves coefficient $b$ in the runoff coefficient formula, initial abstraction $I_{0}$, coefficients $\alpha, \beta, \gamma, \delta$ in the storage coefficient formula (hydrologic module) and Manning coefficient $n$ (hydraulic module). Initial values and variation range for parameters were determined by means of an accurate literature analysis. Geometrical properties of subcatchments are derived with GIS and aereal photographs and they are considered as fixed data.

Single-event calibration is performed and validated with a selection of rainfall events that proved to be uniform within the basin, to avoid problems coming from spatial variation of rain depth. The chosen objective function is the Nash-Sutcliffe efficiency, but peak and volume errors and square sum of errors are computed as well to have an in-depth look at the efficacy of calibration. Results of calibration for ASA basin are highly satisfactory in terms of peaks and volumes reproduction and overall shape of the hydrograph, both for the calibration and for the validation event.

References

ASCE (1993), Criteria for evaluation of watershed models, J. Irrig. Drain. Eng. ASCE 119, 3, 429-442.

Aubert, D., C. Loumagne, and L. Oudin (2003), Sequential assimilation of soil moisture and streamflow data in a conceptual rainfall-runoff model, J. Hydrol. 280, 1-4, 145-161, DOI: 10.1016/S0022-1694(03)00229-4. 
Bagirov, A.M., A.F. Barton, H. Mala-Jetmarova, A.Al Nuimat, S.T. Ahmed, N. Sultanova, and J. Yearwood (2013), An algorithm for minimization of pumping costs in water distribution systems using a novel approach to pump scheduling, Math. Comput. Model. 57, 3-4, 873-886, DOI: 10.1016/ j.mcm.2012.09.015.

Barco, J., K. Wong, and M. Strenstrom (2008), Automatic calibration of the U.S. EPA SWMM model for a large urban catchment, J. Hydraul. Eng. 134, 4, 466-474, DOI: 10.1061/(ASCE)0733-9429(2008)134:4(466).

Beven, K., and A. Binley (1992), The future of distributed models: model calibration and uncertainty prediction, Hydrol. Process. 6, 3, 279-298, DOI: 10.1002/hyp.3360060305.

Bossard, M., J. Feranec, and J. Othael (2000), CORINE Land Cover technical guide - Addendum 2000, Technical Report N. 40, European Environment Agency, Copenaghen, Denmark.

Brocca, L., F. Melone, T. Moramarco, W. Wagner, V. Naeimi, Z. Bartalis, and S. Hasenauer (2010), Improving runoff prediction through the assimilation of the ASCAT soil moisture product, Hydrol. Earth Syst. Sci. 14, 10, 18811893, DOI: 10.5194/hess-14-1881-2010.

Brun, R., P. Reichert, and H.R. Künsch (2001), Practical identifiability analysis of large environmental simulation models, Water Resour. Res. 37, 4, 1015-1030, DOI: 10.1029/2000WR900350.

Butler, D., and J.W. Davies (2004), Urban Drainage, 2nd ed., CRC Press.

Cheng, C.T., M.Y. Zhao, K. W. Chau, and X.Y. Wu (2006), Using genetic algorithm and TOPSIS for Xinanggjiang model calibration with a single procedure, J. Hydrol. 316, 1-4, 129-140, DOI: 10.1016/j.jhydrol.2005.04.022.

Clark, C.O. (1945), Storage and the unit hydropgraph, Trans. ASCE 110, 1419-1446.

Cleveland, R., S. Cleveland, J.E. McRae, and I. Terpenning (1990), STL: A Seasonal-trend decomposition procedure based on Loess, J. Official Stat. 6, 1, 333.

Confalonieri, R., G. Bellocchi, S. Bregaglio, M. Donatelli, and M. Acutis (2010), Comparison of sensitivity analysis techniques: a case study with the rice model WARM, Ecol. Modell. 221, 16, 1897-1906, DOI: 10.1016/ j.ecolmodel.2010.04.021.

Danish Hydraulic Institute (2002), MOUSE Surface Runoff Models Reference Manual, Horsholm, Denmark.

Desbordes, M. (1974), Réflexions sur les méthodes de calcul des réseaux urbains d'assainissement pluvial. Ph.D. Thesis, University of Montpellier 2, France (in French).

Desbordes, M. (1975), Un essai de modélisation des phénomènes de ruissellement pluvial urbain, Tecniques et Sciences Municipales 70, 3, 121-126 (in French). 
Freni, G., G. Mannina, and G. Viviani (2008), Uncertainty in urban stormwater quality modelling: the effect of acceptability threshold in GLUE methodology, Water Res. 42, 8-9, 2061-2072, DOI: 10.1016/j.watres.2007.12.014.

Freni, G., G. Mannina, and G. Viviani (2009), Identifiability analysis for receiving water body quality modelling, Environ. Modell. Softw. 24, 1, 54-62, DOI: 10.1016/j.envsoft.2008.04.013.

Gironàs, J., L.A. Roesner, L.A. Rossman, and J. Davis (2010), A new applications manual for the Storm Water Management Model (SWMM), Environ. Modell. Softw. 25, 6, 813-814, DOI: 10.1016/j.envsoft.2009.11.009.

Green, I.R.A., and D. Stephenson (1986), Criteria for comparison of single event models, Hydrol. Sci. J. 31, 3, 395-411, DOI: 10.1080/02626668609491056.

H.R. Wallingford Ltd. (1997), HydroWorks On-line Manual, Wallingford, U.K.

Inman, J. (2000), Lagtime relations for urban streams in Georgia, Report 00-4049, U.S. Geological Survey, Water-Resources Investigations, Atlanta, USA.

Jawed, K. (1973), Comparison of methods of deriving unit hydrographs, M.Sc. Thesis, Colorado State University, USA.

Kleidorfer, M. (2010), Uncertain Calibration of Urban Drainage Models, Innsbruck University Press.

Kucherenko, S., M. Rodriguez-Fernandez, C. Pantelides, and N. Shah (2009), Monte Carlo evaluation of derivative-based global sensitivity measures, Reliabil. Eng. Syst. Safety 94, 1135-1148.

Kuczera, G., and E. Parent (1998), Monte Carlo assessment of parameter uncertainty in conceptual catchment models: the Metropolis algorythm, J. Hydrol. 211, 1-4, 69-85, DOI: 10.1016/S0022-1694(98)00198-X.

Lim., K.J., B.A. Engel, S. Muthukrishnan, and J. Harbor (2006), Effects of initial abstraction and urbanization on estimated runoff using CN technology, J. Am. Resour. Assoc. 42, 3, 629-643, DOI: 10.1111/j.1752-1688.2006.tb04481.x.

Mancipe-Munoz, N.A., S.G. Buchberger, and M.T. Suidan (2011), Calibration of distributed rainfall-runoff model in Hamilton County, Ohio. In: On Modeling Urban Water Systems, CHI Press, Toronto, 177-191.

Mancipe-Munoz, N.A., S.G. Buchberger, M.T. Suidan, and T. Lu (2014), Calibration of rainfall-runoff model in urban watersheds for stormwater management assessment, J. Water Resour. Plan. Manag. 140, 6, 05014001, DOI: 10.1061/ (ASCE)WR.1943-5452.0000382.

Mandenius, C.F., and N.J. Titchener-Hooker (eds.) (2013), Measurement, Monitoring, Modelling and Control of Bioprocesses, Springer, Berlin.

Mannina, G., G. Freni, G. Viviani, S. Saegrov, and L.S. Hafskjold (2006), Integrated urban water modelling with uncertainty analysis, Water Sci. Technol. 54, 6-7, 379-386, DOI: 10.2166/wst.2006.611.

Mantovan, P., and E. Todini (2006), Hydrological forecasting uncertainty assessment: incoherence of the GLUE methodology, J. Hydrol. 330, 1-2, 368-381, DOI: 10.1016/j.jhydrol.2006.04.046. 
Martin, P.H., E.J. LeBoeuf, J.P. Dobbins, E.B. Daniel, and M.D. Abkwitz (2005), Interfacing GIS with water resource models: a state-of-the-art review, J. Am. Water Resour. Assoc. 41, 6, 1471-1487, DOI: 10.1111/j.1752-1688.2005. tb03813.x.

Martinec, J., and A. Rango (1989), Merits of statistical criteria for the performance of hydrological models, Water Resour. Bull. 25, 2, 421-432.

McCuen, R.H. (1982), A Guide to Hydrologic Analysis Using SCS Methods, Prentice-Hall, Inc.

McEnroe, B.M., and H. Zhao (1999), Lag times and peak coefficients for rural watersheds in Kansas, Report No. K-TRAN: KU-98-1, University of Kansas, USA.

Melching, C.S., and J.S. Marquardt (1997), Equations for estimating synthetic unithydrograph parameter values for small watersheds in Lake County, Illinois, USGS Open-File Report 96-474, U.S. Geological Survey.

Nash, J.E., and J.V. Sutcliffe (1970), River flow forecasting through conceptual models. Part 1 - A discussion of principles, J. Hydrol. 10, 3, 282-290, DOI: 10.1016/0022-1694(70)90255-6.

Niemczynowicz, J. (1987), Storm tracking using rain gauge data, J. Hydrol. 93, 1-2, 135-152, DOI: 10.1016/0022-1694(87)90199-5.

Rao, R.A., and J.W. Delleur (1974), Instantaneous Unit Hydrographs, peak discharges and time lags in urban basins, Hydrol. Sci. J. 19, 2, 185-198, DOI: 10.1080/02626667409493898.

Rao, R.A., J.W. Delleur, and B.S.P. Sarma (1972), Conceptual hydrologic models for urbanizing basins, J. Hydraul. Div. 98, 7, 1205-1220.

Reichert, P., and P. Vanrolleghem (2001), Identifiability and uncertainty analysis of the River Water Quality Model No. 1 (RWQM1), Water Sci. Technol. 43, 7, 329-338.

Rossman, L.A. (2004), Storm Water Management Model User's Manual Version 5.0, U.S. Environmental Protection Agency (EPA).

Sabol, G.V. (1988), Clark unit hydrograph and R-parameter estimation, J. Hydraul. Eng. 114, 1, 103-111, DOI: 10.1061/(ASCE)0733-9429(1988)114:1(103).

Saltelli, A., M. Ratto, T. Andres, F. Campolongo, J. Cariboni, D. Gatelli, M. Saisana, and S. Tarantola (2008), Global Sensitivity Analysis. The Primer, John Wiley \& Sons.

Sarma, P.B.S., J.W. Delleur, and A.R. Rao (1973), Comparison of rainfall-runoff models for urban areas, J. Hydrol. 18, 3-4, 329-347, DOI: 10.1016/00221694(73)90056-5.

Savić, D.A., J. Bicik, and M.S. Morley (2011), A DSS Generator for multiobjective optimisation of spreadsheet-based models, Environ. Modell. Softw. 26, 5, 551-561, DOI: 10.1016/j.envsoft.2010.11.004.

Schaake, J.C., J.C. Geyer, and J.W. Knapp (1967), Experimental evaluation of rational method, J. Hydraul. Div. 93, 6, 353-370. 
Schreider, S.Y., P.C. Young, and A.J. Jakeman (2001), An application of the Kalman filtering technique for streamflow forecasting in the Upper Murray Basin, Math. Comput. Modell. 33, 6-7, 733-743, DOI: 10.1016/S08957177(00)00276-4.

Stedinger, J.R., R.M. Vogel, S.U. Lee, and R. Batchelder (2008), Appraisal of the generalized likelihood uncertainty estimation (GLUE) method, Water Resour. Res. 44, 12, W00B06, DOI: 10.1029/2008WR006822.

Stisen, S., and I. Sandholt (2010), Evaluation of remote-sensing-based rainfall products through predictive capability in hydrological runoff modelling, Hydrol. Process 24, 7, 879-891, DOI: 10.1002/hyp.7529.

Straub, T.D., C.S. Melching, and K.E. Kocher (2000), Equations for estimating Clark unit hydrograph parameters for small rural catchments in Illinois, Report 00-4184, Water-Resources Investigations, USGS.

Tan, S.B.K., L.C.H. Chua, E.B. Shuy, E.Y. Lo, and L.M. Lim (2008), Performances of rainfall-runoff models calibrated over single and continuous storm flow events, J. Hydraul. Eng. 13, 7, 597-607, DOI: 10.1061/(ASCE)10840699(2008)13:7(597).

Thorndahl, S., C. Johansen, and K. Schaarup-Jensen (2006), Assessment of runoff contributing catchment areas in rainfall runoff modelling, Water Sci. Technol. 54, 6-7, 49-56, DOI: 10.2166/wstr=.2006.621.

Thorndahl, S., K.J. Beven, J.B. Jensen, and K. Schaarup-Jensen (2008), Event based uncertainty assessment in urban drainage modelling, applying the GLUE methodology, J. Hydrol. 357, 3-4, 421-437, DOI: 10.1016/j.jhydrol.2008.05. 027.

U.S. Army Corps of Engineers (1985), HEC-1 flood hydrograph package, Hydrologic Engineering Center, Davies, California, USA.

Wisner, P., and J.C. P'ng (1983), IMPSWM urban drainage modelling procedures, Department of Civil Engineering, University of Ottawa, Canada.

Received 4 August 2015

Received in revised form 3 November 2015

Accepted 14 December 2015 